\title{
Relevant Aspects To Promote Teacher Awareness in the Pedagogical Orchestration of Learning Activities Where Students Move
}

Claudio Cleverson de Lima ( $\sim$ claudiodelima@yahoo.com.br)

UNISINOS https://orcid.org/0000-0003-0762-9680

Leonel Caseiro Morgado

Universidade Aberta de Portugal

Eliane Schlemmer

Unisinos: Universidade do Vale do Rio dos Sinos

\section{Research Article}

Keywords: awareness, learning, monitoring, mobile activities, pedagogical orchestration

Posted Date: February 17th, 2021

DOl: https://doi.org/10.21203/rs.3.rs-175631/v1

License: (c) (i) This work is licensed under a Creative Commons Attribution 4.0 International License.

Read Full License 


\title{
RELEVANT ASPECTS TO PROMOTE TEACHER AWARENESS IN THE PEDAGOGICAL ORCHESTRATION OF LEARNING ACTIVITIES WHERE STUDENTS MOVE
}

\author{
blind review ${ }^{1}$ \\ blind review ${ }^{2}$ \\ blind review ${ }^{3}$
}

\begin{abstract}
The pedagogical monitoring of activities involving spatial movement of students represents a teaching challenge due to events taking place outside the visual reach of the teacher. We present a literature review in which observational aspects are relevant to promote teacher awareness in these activities, from a perspective of awareness within the field of CSCW Computer Supported Cooperative Work. We also identified instruments and situations associated with those aspects of awareness. Results are presented via thematic analysis, clarifying the relevance of aspects related to Motivation/Engagement, Location/Path, Execution of the Activity, Interaction/Cooperation, and Results/Feedback. This clarification may contribute towards the development of learning orchestration protocols and information systems which support teachers in the collection and analysis of awareness-supporting data, contributing to teacher awareness of what occurs in these activities and allowing greater freedom and assertiveness in the pedagogical orchestration.
\end{abstract}

\footnotetext{
${ }^{1}$ blind for review

${ }^{2}$ blind for review

${ }^{3}$ blind for review
}

[Running head] Teacher awareness in pedagogical orchestration of mobile learning 
Keywords: awareness, learning, monitoring, mobile activities, pedagogical orchestration.

\section{INTRODUCTION}

Learning activities involving students moving around derive from various conceptual, metaphorical, temporal, and technological perspectives (Nichele \& Schlemmer, 2015), having as characteristics, in addition to movement, the fact of not occuring in a fixed, predetermined location (O’Malley et al., 2005). Such activities are important, from a pedagogical point of view, for the development of physical and cognitive aspects, but also for the development of cooperative and interpersonal skills (Hawxwell et al., 2019; MacQuarrie, 2018; Reiss, 2012). However, with students moving around, outside the visual span of the teacher, it becomes challenging to monitor these activities (Munoz-Cristobal et al., 2015; Pishtari et al., 2019).

There are several other pedagogical practices through which students are also not in static predetermined locations, yet not requiring students to be moving during the activity. Most activities labeled as mobile learning are of this genre: students are not in a predetermined location, they move around, but not necessarily during the activity itself (Crompton, 2013). A student in mobile learning may simply be performing traditional pedagogical activities, as reading or writing, while sitting in undetermined places. Our focus is on pedagogical activities in

which there is spatial movement of students throughout the learning process (O'Malley et al., 2005).

Thus, this research aims to identify, describe, and analyze which aspects are relevant for monitoring, to support teacher awareness in the pedagogical orchestration of learning activities where students move, it also aims to ascertain the situations when teachers become aware of

[Running head] Teacher awareness in pedagogical orchestration of mobile learning 
those aspects and which instruments are used for that purpose. This aim contributes to solving the challenge teachers face when orchestrating such pedagogical activities (Dillenbourg, 2013; Pishtari, G. et al., 2019; Wild, 2010), promoting teacher awareness (Schmidt, 2002) of the course of the activities, through digital technologies (Munoz-Cristobal et al., 2015; Prieto, 2012; Rojas et al., 2012; Roschelle et al., 2013) to support the management of learning activities where students move.

The ability to orchestrate learning activities where students move is crucial for their feasibility, because teachers need to know what students are doing in different spaces: where they are located, what activities have been completed, the time required for them, the difficulties, the activity status, and other critical information for pedagogical orchestration. This awareness of what is happening in the activity enables teachers to intervene. Teacher awareness of the progress of the learning activities is the main aspect to be improved in the relationship between awareness and learning (Munoz-Cristobal et al., 2015) and the monitoring of these activities is essential in the orchestration (Prieto, 2012; Prieto et al., 2011; Roschelle et al., 2013).

When students move in learning activities, the orchestration difficulties increase, since visual contact between teachers and students is substantially reduced or even absent, depending on the geographical space and the distance between the actors involved in the activity. Digital technologies can help, but for that it is necessary to know which aspects to monitor, in order to develop models and systems that efficiently contribute to teacher awareness for pedagogical orchestration. This is one of the research problems in the field of awareness in cooperative environments (Schmidt, 2002) which is particularly relevant for the field of education.

[Running head] Teacher awareness in pedagogical orchestration of mobile learning 
Therefore, we carried out a systematic literature review combining the concept of awareness in the context of Computer Supported Cooperative Work (CSCW) with the field of education. This combination identified which aspects are relevant to promote teacher awareness of the ongoing process of learning activities where students move. Specifically, we proceeded to 1) collect, analyse, and categorize these aspects, 2) identify the situations (real time, post-activity or a combination of them) when the teacher becomes aware of the aspects, and 3) identify the instruments used by teachers for this.

Section 2 presents the theoretical framework, section 3 describes the systematic methodology review, and section 4 presents the results. These results are analyzed and discussed in Section 5. Section 6 presents the conclusions of this paper and suggestions for future research.

\section{THEORETICAL FRAMEWORK}

Awareness is the way in which cooperating actors, while acting individually, pay attention to the context, aligning and integrating their actions towards the joint work effort (Schmidt, 2002). By keeping themselves aware of the actions of others, the actors adjust their own activities (Gutwin \& Greenberg, 2002) without interrupting their line of action in an apparently effortless way (Dourish \& Bly, 1992). Besides this adaptation, when coordinating cooperative activities, and the adoption of technology by individuals or groups in a specific situation, awareness is one of the central dimensions of the CSCW theoretical framework (Bannon, 1993). The strict understanding of awareness as practices through which cooperative activities are aligned and integrated in a seamless blended way, is specific to CSCW. This field studies systems, technologies, and prototypes (and their design) which aim is to expand the cooperation between

[Running head] Teacher awareness in pedagogical orchestration of mobile learning 
the actors in their distributed environments, and recognizes the critical importance of awareness in the development of support systems for cooperation (Schmidt, et al., 2011).

Under this perspective, awareness is not a distinct mental state that exists independently of the action, but rather related to a person's notion of something, the attention they pay to the context of joint effort: an integrated state of practice, which should be inquired as such (Schmidt, 2002). Awareness as "[...] understanding of the activities of others, which provides a context for their own activity" (Dourish \& Bellotti, 1992, p. 107) considers that individuals working together need to gain some level of knowledge about the sharing and progress of joint activities. The fluidity and naturalness of cooperation based on awareness of the progress of work between actors is something tacit, which enables monitoring the work of others without requiring them to provide deliberate feedback (Gutwin \& Greenberg, 2002).

Awareness is not the product of passively acquired information, but a highly active and qualified practice: competent professionals are able to align and integrate their activities because they are aware of the scenario (Heath et al., 2002; Robertson, 2002). It is not paradoxical to be involved in a line of action and, at the same time, make sense of and pay attention to what goes on beyond it. To do something and to be aware of other relevant events are not two separate lines of action, but specific ways of pursuing the same objective (Schmidt, 2002). When an actor perceives a colleague doing something in a shared environment, it monitors the work of that other person and exhibits aspects of its own work by non-intrusive interaction that is appropriate to the situation, the so-called "appropriate intrusion". This way, actors are not ignorant or uninterested expectators, but rather actively engaged in the activities and objectives to be achieved.

[Running head] Teacher awareness in pedagogical orchestration of mobile learning 
Awareness studies represent a challenge in the field of design and orchestration of learning activities, which can take advantage of computer systems which enable extrapolating direct observations towards new possibilities for monitoring emerging and sustaining of awareness, stimulating engagement (Gaver, 2002), feedback (Mark, 2002), and social interaction (Heath et al., 2002). Regarding the attention actors pay to the social context where both action and interaction occur, informal meetings are useful for bonding, forming alliances, and sharing, generating interactions and shared culture, which are important for politics and management, and fundamental for education (Dourish \& Bly, 1992), where interaction, socialization and cooperation thriving learning.

The realization which it is not a miracle that actors understand each other's actions turns awareness a researchable problem (Schmidt, 2002). To apply it to activities where students move, it is necessary to determine which aspects of these activities are relevant to the teacher's awareness, enabling them to understand and support cooperative work with students: monitoring for pedagogic orchestration; processes for productive coordination of interventions within learning activities at different levels (individual, group, class), contexts (classroom, home, laboratory, field trips, etc.) and types of media (with or without digital technologies, images, videos, etc.) (Dillenbourg et al., 2009).

Under this perspective, monitoring constitutes a central aspect in the management of activities where students move (Lima et al., 2020). This can be enhanced through digital technological devices to support data collection and processing (Dillenbourg, 2013; Schmidt, 2002), and thus assisting the teacher in pedagogical orchestration. Through it, teachers and other

[Running head] Teacher awareness in pedagogical orchestration of mobile learning 
actors design, manage, adapt, and evaluate learning activities, aiming to maximize learning within contextual constraints (Prieto, 2012).

Orchestration helps teachers create, execute, monitor, and manage learning situations in educational environments (Prieto et al., 2011; Roschelle et al., 2013). In activities where students move throughout large spaces, it is not uncommon for teachers to lose awareness of where students are and what they are doing. In addition to monitoring, it is important to keep students motivated and engaged. Motivation appears as an indication of willingness to participate in the proposed tasks, and engagement as a relationship between this willingness and active participation in the proposed activities, stimulated by extrinsic (rewards) or intrinsic (excitement, fun) aspects (Chou, 2015). Engagement involves aspects such as behavioral: (interest, involvement, concentration, attention, and participation in the activity), cognitive (motivation, immersion, mental effort, and concentration aiming at appropriating information), and emotional (enthusiasm, fun, satisfaction, and belonging). Engagement is an essential component for the success of educational processes (Fredriks et al., 2004).

Once students are motivated and engaged, teachers need to provide support and feedback during the activities. Regarding group behavior, feedback is essential for accommodating processes and encouraging learning and cooperation. Notifications are effective reminders of group plans during the activities, reinforcing positive actions and occasional help when in doubt (Mark, 2002). Formative feedback contributes in pedagogical orchestration, guiding students towards appropriation and learning, focusing on promoting student's knowledge and learning (Shute, 2007).

[Running head] Teacher awareness in pedagogical orchestration of mobile learning 
These monitoring needs in learning activities where students move require teachers to pay attention to diverse aspects of learning and contexts. Since many actions occur during such activities, teachers must realize which aspects are relevant for awareness, and which are not. The purpose of this research was to determine which are these aspects.

\section{METHOD}

We conducted a systematic literature review (Kitchenham \& Charters, 2007) aiming to determine which aspects are relevant for teacher awareness in learning activities where students move, and hence prioritized for monitoring. We used Google Scholar with the search terms "outdoor activities management", “outdoor learning management", “mobile learning management", and "mobile activities management", validating the results with the inclusion and exclusion criteria in Table 1. The choice of Google Scholar, to the detriment of other aggregators of scientific production, was meant to obtain a wider range of results, by covering a greater diversity of sources. However, it also required the EC4 exclusion criterion (exclusion of non-peer reviewed articles), for the sake of data quality.

\section{Table 1}

Inclusion and exclusion criteria

[available in the requested attached file ]

[Running head] Teacher awareness in pedagogical orchestration of mobile learning 
After applying the search and inclusion/exclusion protocol, the resulting corpus of articles was submitted to a compliance check, verifying incorrect data source, referencing data, and merging duplicated articles. All papers were then read in their entirety, extracting:

a) the aspects observed in learning activities where students move;

b) the instruments used for monitoring those aspects;

c) the occasions in which the teacher became aware of those aspects (T1: real-time, T2: post-activity, and T3: some combination of $\mathrm{T} 1$ and $\mathrm{T} 2$ ).

\section{RESULTS}

The result of applying the inclusion and exclusion criteria of Table 1 is presented below (Table 2), with the number of papers resulting from each stage, followed by the resulting size of the paper corpus. The final corpus is presented in Table 3 by decreasing order of year of publication.

\section{Table 2}

Inclusion and Exclusion Criteria application

[available in the requested attached file ]

\section{Table 3}

Corpus of selected papers of the systematic review of the literature [available in the requested attached file ]

[Running head] Teacher awareness in pedagogical orchestration of mobile learning 
After a complete reading of the 32 papers, a total of 121 aspects were extracted. These are aspects in support of teacher awareness of learning activities where students move. They were grouped by similarity to eliminate overlaps, resulting in a total of 49 aspects (Table 4):

\section{Table 4}

Aspects to observe in mobile activities and its absolute frequency

[available in the requested attached file ]

The resulting aspects were also classified according to the situations to which the teacher became aware of (Graphic 1). Those were:

T1: real-time (awareness occurred during the activity)

T2: post-activity (awareness occured after the activity ended)

T3: mixed (awareness occured in some combination of T1 and T2).

\section{Graphic 1}

Teacher awareness occasions for the resulting aspects

[available in the requested attached file ]

The instruments used to monitor the aspects were also grouped by similarity, to eliminate overlap, into eight categories, shown in Table 5 and Graphic 2.

\section{Table 5}

[Running head] Teacher awareness in pedagogical orchestration of mobile learning 
Instruments used to monitor the teacher awareness regarding mobile activities

[available in the requested attached file ]

\section{Graphic 2}

Instruments used to monitor awareness aspects in learning activities where students move [available in the requested attached file ]

\section{ANALYSIS AND DISCUSSION}

The literature review resulted in 49 relevant aspects to be monitored to support the awareness of the teacher during the pedagogical orchestration of activities in movement (Table 6). Seeking to structure the analysis of these aspects and present a guideline of aspects to be observed in mobile learning activities, they were grouped by thematic analysis into five themes of aspects to be monitored (table 6):

\section{Table 6}

Thematic grouping of aspects

[available in the requested attached file ]

To identify the prevalence of aspects by theme (graphic 3), two major groups are observed: higher prevalence of the themes Execution (T3) and Location and Path (T2), representing together more than half of the aspects (52\%), and lower prevalence of the themes

[Running head] Teacher awareness in pedagogical orchestration of mobile learning 
Motivation and Engagement (T1), Interaction and Cooperation (T4) and Feedback and Results (T5), representing together $48 \%$ of the issues raised.

\section{Graphic 3}

Prevalence of thematic aspects to be observed in mobile activities

[available in the requested attached file ]

The T2 and T3 themes represent the main concern in the pedagogical orchestration (Prieto, 2012; Prieto et al., 2011; Roschelle et al., 2013) of mobile learning activities, highlighting being crucial that the teacher be aware of activity execution by the students and their location and path. To know where students are during the activity (T2), their trajectory and digital footprints left by them in their browsing promotes teacher awareness (Schmidt, 2002), meaning more freedom and assertiveness in the teacher pedagogical orchestration. In the activity execution (T3) it is necessary to be aware if activities were or not executed, the duration of execution, the status of task execution and the activity (as a whole), which information students had access to or collected executing the activity, which technologies were appropriated, which difficulties were found and needs of assistance.

The themes $\mathrm{T} 1, \mathrm{~T} 4$ and $\mathrm{T} 5$, with less prevalence, represent aspects less present in the literature review presented here, which may mean less relevant aspects, or else, areas that demand more research effort. In theme T1, motivation (Chou, 2015) expresses the student's willingness to carry out the activity, while engagement (Fredriks et al., 2004; Gaver, 2002; Piaget, 1979; Rand et al., 2009) promotes involvement and active agency in carrying out activities. The awareness of

[Running head] Teacher awareness in pedagogical orchestration of mobile learning 
the teacher is promoted by aspects of interest, motivation, participation, concentration, fun, immersion, engagement and students' perspectives or preferences.

In the $\mathrm{T} 4$ theme, the interactive-cooperative aspects are present in the area of the CSCW (Dillenbourg, 2013; Gaver, 2002; Heath et al., 2002; Schmidt, 2002) as well as educational area, with the interaction (Rand et al., 2009; Warneken \& Tomasello, 2007) and the cooperation (Rand et al., 2009; Rand \& Nowak, 2013; Warneken \& Tomasello, 2007). The awareness of the teacher in these aspects is important because interaction and cooperation are closely related to the way the actors interact and cooperate to achieve the proposed objectives which in education correspond to learning.

Teachers awareness allows these interactive-cooperative processes to be carried out in a tacit and discreet way, without affecting the fluidity and naturalness of the activity's execution (Gutwin \& Greenberg, 2002; Schmidt, 2002). The teacher being aware of these aspects is important because it makes it possible to identify the intervention-mediation point in the pedagogical orchestration of the activity, and this awareness is promoted by observing aspects of teamwork, interaction, cooperation, information sharing, communication and connection.

The T5 theme presents feedback and results as a set of closely related aspects. Feedback appears as an important reinforcement of cooperative actions (Mark, 2002), either by emphasizing positive results in students, or punctually assisting in doubts. It should not be taken in the prescriptive sense, but as a follow-up of the student in promoting learning (Shute, 2007)). In addition to the results themselves, aspects such as assessment, effectiveness, and quality of learning, and a sense of victory and accomplishment help promote the teacher's awareness in terms of results.

[Running head] Teacher awareness in pedagogical orchestration of mobile learning 
In relation to the temporal moment in which teachers become aware of these aspects (graphic 3 ), the data shows that more than half $(56,3 \%)$ of the aspects were observed in real-time (T1), and it indicates that digital systems and technologies may help real-time mobile learning monitoring: this option covers the pedagogical concern in monitoring the mobile activity as a whole, and not only the result. Aspects related to appreciation of activities by students can be analyzed in the post-activity (T2), but the ideal is to be collected, processed, and informed to the teacher in real-time, since students may need feedback and teachers may not be aware of it, the learning opportunity could be compromised. The third possibility is the mixed temporal moment (T3), in which aspects are monitored in real-time and confirmed in post-activity.

Regarding the instruments used for the monitoring of relevant aspects for the teacher awareness in mobile learning (Table 4), it is possible to detect that data coming from digital systems are the majority (54\%), a result which is closely related to temporality observations $\mathrm{T} 1$, or real-time (56\%). The instruments used to observe aspects are specific systems, web dashboards or sheets, 3D avatars, and geolocation. Secondly, manual observation and mapping emerge, with prevalence of $15 \%$. Observation is an important element of monitoring, but it becomes less efficient in mobile activities in wide open spaces, and performed by many students, individually or in teams. Likely, manual mapping, which works in small groups and spaces, is not an option in wide spaces. Currently, with a lot of digital technological resources, which allow to automatize the mapping in real time, it would be expected the appropriation of them would promote the awareness of teachers regarding mobile activities.

The instruments: digital systems/web dasboard/web tools/avatar3D/geolocation (I1 inTable 4) appear as data collection instruments pre and post-activity, and, therefore, not very

[Running head] Teacher awareness in pedagogical orchestration of mobile learning 
efficient to observe the activity process itself, as they will interrupt the students learning action sequence. Aside from this kind of instruments, as well videos, texts, and images produce results which only come for the teacher after the fact occurrence and in raw format, demanding time for the analysis. We agree that when this data is received in a consolidated form, the time for the analysis is reduced (Pishtari et al., 2019) contributing to teachers to offer information and assistance for the students at the appropriate moment.

\section{CONCLUSÕES}

The orchestration of mobile learning activities represents a challenge for teachers and the research question sought to identify which aspects are to be observed to promote the awareness of the teacher in this type of activity. The issue emerges both from the observation of monitoring as a central problem in monitoring these activities (Prieto, 2012; Prieto et al., 2011; Roschelle et al., 2013, Lima et al., 2020) as well as more specific problems in monitoring these aspects to inform stakeholders of the educational process, notably teachers (Pishtari et al., 2019). The identification of these aspects advances knowledge and discussion in the field by enabling greater assertiveness and direction in the monitoring of activities and in their orchestration, whether using analog solutions, conventional digital technology or emerging digital technologies.

The awareness of the teacher regarding what is happening at the time of the activity may provide them with the possibility to provide help or feedback promptly, promoting learning and avoiding demotivation or drop outs, turning the students monitoring on the mobile learning activities essencial. After extracting and classifying the aspects into themes, as well as the

[Running head] Teacher awareness in pedagogical orchestration of mobile learning 
temporality in which teacher awareness occurred and the instruments used in this observation, resulted in 5 themes and respective aspects to be observed in the learning activities in movement:

- T1 - Motivation and engagement: motivation, interest, participation, concentration, immersion, fun, engagement, perspectives, preferences, students behavior;

- T2 - Location and path: location, path, footprint, exploration, navigation, hotspot, triggering information

- T3 - Activity execution: activity execution, execution time, task status, progress status, data/information collection, content access, lab experiences, help, difficult, technological appropriation, usability, artifacts use, app use, scientific exploration)

- T4 - Interaction and Cooperation: interaction, cooperation, team report, sharing information, communication, connection;

- T5: Results and Feedback: results score, assignment, assessment, peer assessment, learning effectiveness, learning quality, learning satisfaction, knowledge construction, perception, post-test information, feedback, victorious feeling, achievement).

We emphasize that the aspects that compose the themes are not definitive and may receive aspects not mentioned here, but they may emerge from future experiences of mobile learning activities. As long as the description of each theme is respected, new aspects may be framed in the presented themes, or, eventually, constitute new themes with aspects not addressed, increasing knowledge in the area. We emphasize that, as a result of this research and the literature review, these were the themes that emerged.

[Running head] Teacher awareness in pedagogical orchestration of mobile learning 
Concerning temporality, about half of the aspects promote awareness in real-time, such as on-site observation or supported by specific systems, mobile devices, dashboards, web tools, and virtual worlds. Observation and manual mapping persist, but represent greater workload and have limited effectiveness in monitoring moving activities. Aspects that promote post-activity teaching awareness are useful in the evaluation of the process by students and future improvements but less beneficial in real-time pedagogical awareness and orchestration, which would enable the pedagogical orchestration during the activity itself.

It is noteworthy that the analysis of these aspects in a practical mobile learning experience is already an ongoing study by the authors. Future research may focus on the design and execution of field activities to deepen the observation of the themes/aspects mentioned here and others. In terms of automation of this monitoring, technological solutions may focus on covering all aspects mentioned through a single system with a lot of resources, but subject to usability, integration, and scalability issues, or in simpler and more focused systems, though would cover fewer aspects. Later and/or complementary advances are configured in the exploration of solutions with simpler technology or emerging digital technologies, among them Internet of Things (IoT). IoT technologies, due to their characteristics of size, connection, and distributed processing in the cloud may cooperate with useful data for the promotion of teacher awareness in the orchestration of mobile learning activities.

\section{ACKNOWLEDGEMENT}

[Running head] Teacher awareness in pedagogical orchestration of mobile learning 
This research was carried out with the support of the Coordenação de Aperfeiçoamento de Pessoal de Nível Superior - Brasil (CAPES) - Financing Code 001. The authors are grateful for the support received.

\section{COMPLIANCE WITH ETHICAL STANDARDS}

\section{Ethical Approval}

Not applicable

\section{Informed Consent}

Not applicable

\section{Conflict of Interest/Competing Interest}

The authors declare that they have no conflict of interest/competing interests.

\section{REFERENCES}

Bannon, L. J. (1993). CSCW: an initial exploration. http://iris.cs.aau.dk/tl_files/volumes/volume05/no1/OCR01_bannon_p3-24.pdf

Chou, Y. (2015, março 1). Octalysis: Complete Gamification Framework - Yu-kai Chou. Yu-Kai Chou: Gamification \& Behavioral Design. https://yukaichou.com/gamification-examples/octalysis-complete-gamification-framewor $\mathrm{k} /$

Crompton, H. (2013). A Historical Overview of M-Learning: Toward Learner-Centered Education. In Z. L. Berge \& L. Muilenburg (Orgs.), Handbook of Mobile Learning ( $1^{\circ} \mathrm{ed}$, p. 3-14). Routledge. https://doi.org/10.4324/9780203118764

[Running head] Teacher awareness in pedagogical orchestration of mobile learning 
Dillenbourg. (2013). Design for classroom orchestration.

https://edisciplinas.usp.br/pluginfile.php/4198724/mod_resource/content/8/Dillenbourg-C E-A8Extra.pdf

Dillenbourg, Jarvela, Sanna, \& Fischer, Frank. (2009). The evolution of research on computer-supported collaborative learning: From design to orchestration. https://link.springer.com/chapter/10.1007/978-1-4020-9827-7_1

Dourish, \& Bellotti. (1992). Awareness and Coordination in Shared Work Spaces. http://www.pensivepuffin.com/dwmcphd/syllabi/info447_au10/readings/Dourish.Awaren ess.CSCW92.pdf

Dourish, \& Bly. (1992). Portholes: Supporting Awareness in a Distributed WorkGroup. http://grouplab.cpsc.ucalgary.ca/saul/601.13/readings/portholes.pdf

Fredriks, Blumenfeld, \& Paris. (2004). School Engagement: Potential of the Concept, State of the Evidence.

https://vpn.uab.pt/https/journals.sagepub.com/doi/pdf/10.3102/00346543074001059

Gaver. (2002). Provocative awareness.

http://www.interaction-venice.com/courses/08-09Lab2/08-09Lab2_uploads/2009/02/gave rprovocativeawareness.pdf

Gutwin, C., \& Greenberg, S. (2002). A Descriptive Framework of Workspace Awareness for Real-Time Groupware. Computer Supported Cooperative Work (CSCW), 11(3-4), 411-446. https://doi.org/10.1023/A:1021271517844

Hawxwell, L., O'Shaughnessy, M., Russell, C., \& Shortt, D. (2019). 'Do you need a kayak to learn outside?': A literature review into learning outside the classroom. Education 3-13,

[Running head] Teacher awareness in pedagogical orchestration of mobile learning 
47(3), 322-332. https://doi.org/10.1080/03004279.2018.1444074

Heath, C., Svensson, M. S., Hindmarsh, J., Luff, P., \& vom Lehn, D. (2002). Configuring Awareness. Computer Supported Cooperative Work (CSCW), 11(3-4), 317-347. https://doi.org/10.1023/A:1021247413718

Kitchenham, \& Charters. (2007). Guidelines for performing Systematic Literature Reviews in Software Engineering. http://jnoll.nfshost.com/cit816-spring-19/topics/slrs/Kitchenham_2007_Guidelines.pdf

Lima, C. C. de, Schlemmer, E., \& Morgado, L. C. (2020). Managing learning in environments where students move: A panorama of problems and contributions. ResearchGate. https://estudogeral.sib.uc.pt/handle/10316/89364

MacQuarrie, S. (2018). Everyday teaching and outdoor learning: Developing an integrated approach to support school-based provision. Education 3-13, 46(3), 345-361. https://doi.org/10.1080/03004279.2016.1263968

Mark,. (2002). Conventions and Commitments in Distributed CSCW Groups. https://www.ics.uci.edu/ gmark/CSCW02-journal.pdf

Munoz-Cristobal, J. A., Jorrin-Abellan, I. M., Asensio-Perez, J. I., Martinez-Mones, A., Prieto, L. P., \& Dimitriadis, Y. (2015). Supporting Teacher Orchestration in Ubiquitous Learning Environments: A Study in Primary Education. IEEE Transactions on Learning Technologies, 8(1), 83-97. https://doi.org/10.1109/TLT.2014.2370634

Nichele, A. G., \& Schlemmer, E. (2015). Mobile Learning and Bring Your Own Device in Chemistry Teaching. INTED2015 Proceedings, 3964-3969. https://library.iated.org/view/GRUNEWALDNICHELE2015MOB

[Running head] Teacher awareness in pedagogical orchestration of mobile learning 
O’Malley, C., Vavoula, G., Glew, J., Taylor, J., Sharples, M., Lefrere, P., Lonsdale, P., Naismith, L., \& Waycott, J. (2005). Guidelines for learning/teaching/tutoring in a mobile environment. 84.

Piaget. (1979). A Construção do real na criança.

Pishtari, G., María Jesús Rodríguez-Triana, \& Terje Väljataga. (2019). Multi-stakeholder Analytics for Learning Design: A Case Study of Location-based Tools.

Pishtari, María Jesús Rodríguez-Triana, \& Terje Väljataga. (2019). Multi-stakeholder Analytics for Learning Design: A Case Study of Location-based Tools.

Prieto. (2012). Supporting orchestration of blended CSCL scenarios in distributed learning environments. https://pdfs.semanticscholar.org/c135/fbc5605a26505d0f0b69278elbf46886d242.pdf

Prieto, Dlab, Martina Holenko, Gutiérrez, Israel, Abdulwahed, Mahmoud, \& Balid, Walid. (2011). Orchestrating technology enhanced learning: A literature review and a conceptual framework. ResearchGate. https://www.researchgate.net/publication/264129336_Orchestrating_technology_enhance d_learning_A_literature_review_and_a_conceptual_framework

Rand, D. G., Dreber, A., Ellingsen, T., Fudenberg, D., \& Nowak, M. A. (2009). Positive interactions promote public cooperation. Science (New York, N.Y.), 325(5945), 1272-1275. https://doi.org/10.1126/science. 1177418

Rand, D. G., \& Nowak, M. A. (2013). Human cooperation. Trends in Cognitive Sciences, 17(8), 413-425. https://doi.org/10.1016/j.tics.2013.06.003

Reiss, M. (2012). Learning Out of the Classroom. https://discovery.ucl.ac.uk/id/eprint/10024050/

[Running head] Teacher awareness in pedagogical orchestration of mobile learning 
Robertson, T. (2002). The Public Availability of Actions and Artefacts. Computer Supported Cooperative Work (CSCW), 11(3-4), 299-316. https://doi.org/10.1023/A:1021214827446

Rojas, Garcia, \& Kloos. (2012). Enhancing Orchestration of Lab Sessions by Means of Awareness Mechanisms. https://core.ac.uk/download/pdf/29405912.pdf

Roschelle, J., Dimitriadis, Y., \& Hoppe, U. (2013). Classroom orchestration: Synthesis. Computers \& Education, 69, 523-526. https://doi.org/10.1016/j.compedu.2013.04.010

Schmidt, Heath, C., \& Rodden C. (2011). Preface_Journal of Computer Software Cooperative Work Journal. https://link.springer.com/article/10.1023/A:1021259125503

Schmidt, K. (2002). The Problem with `Awareness’: Introductory Remarks on `Awareness in CSCW'. Computer Supported Cooperative Work (CSCW), 11(3-4), 285-298. https://doi.org/10.1023/A:1021272909573

Shute, V. J. (2007). Focus on Formative Feedback. ETS Research Report Series, 2007(1), i-47. https://doi.org/10.1002/j.2333-8504.2007.tb02053.x

Warneken, F., \& Tomasello, M. (2007). Helping and Cooperation at 14 Months of Age. https://www.the-brights.net/morality/statement_4_studies/12.\%20Warneken,\%20F.,\%20 \&\%20Tomasello,\%20M.\%20(2007).\%20Helping\%20and\%20cooperation\%20at\%2014\% 20months\%20of\%20age.\%20Infancy,\%2011(3),\%20271-294.pdf

Wild, F. (2010). The STELLAR vision and strategy statement. https://www.academia.edu/36103421/D1.1__The_STELLAR_vision_and_strategy_state ment

[Running head] Teacher awareness in pedagogical orchestration of mobile learning 
Figures

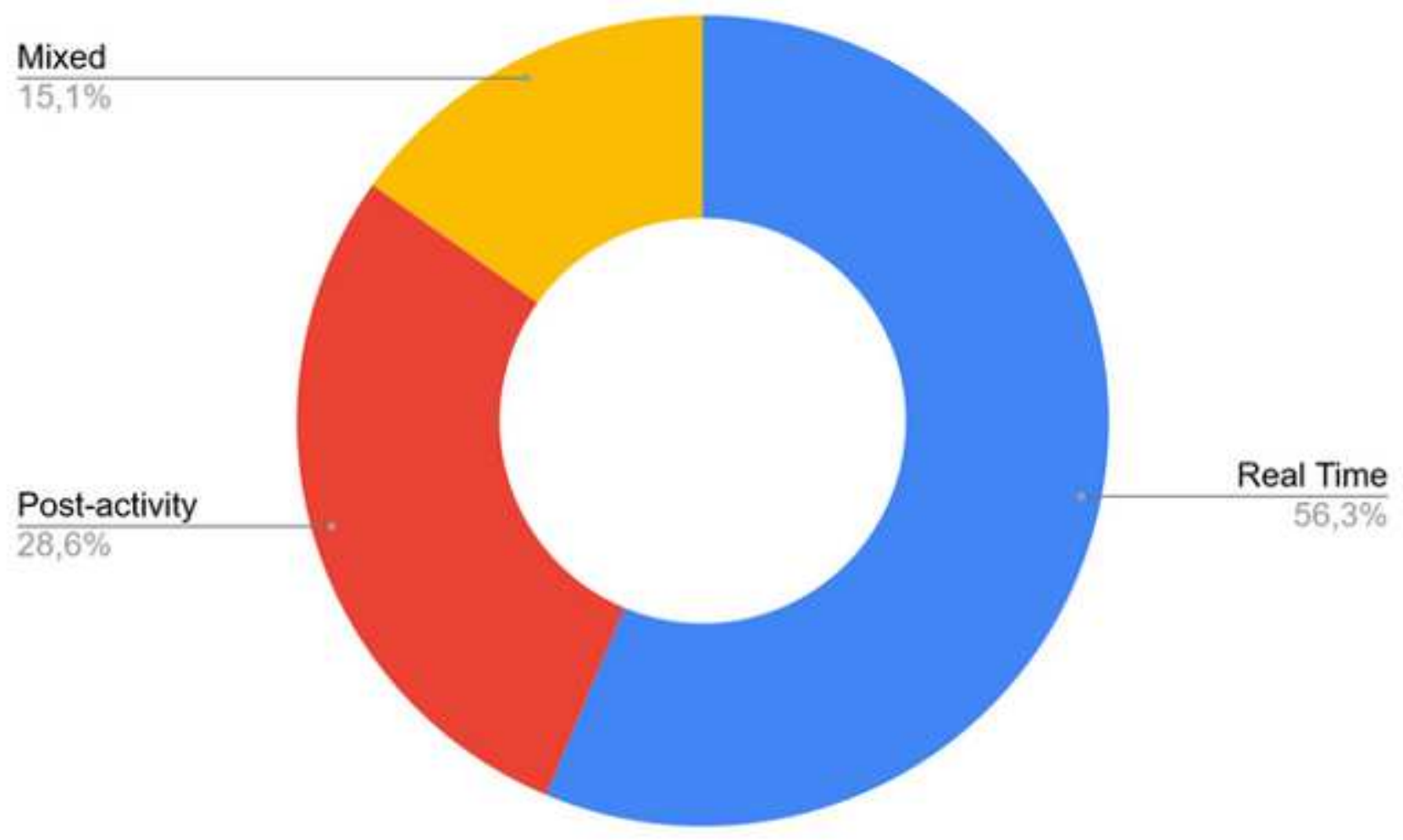

Graphic 1

Figure 1

Teacher awareness occasions for the resulting aspects 


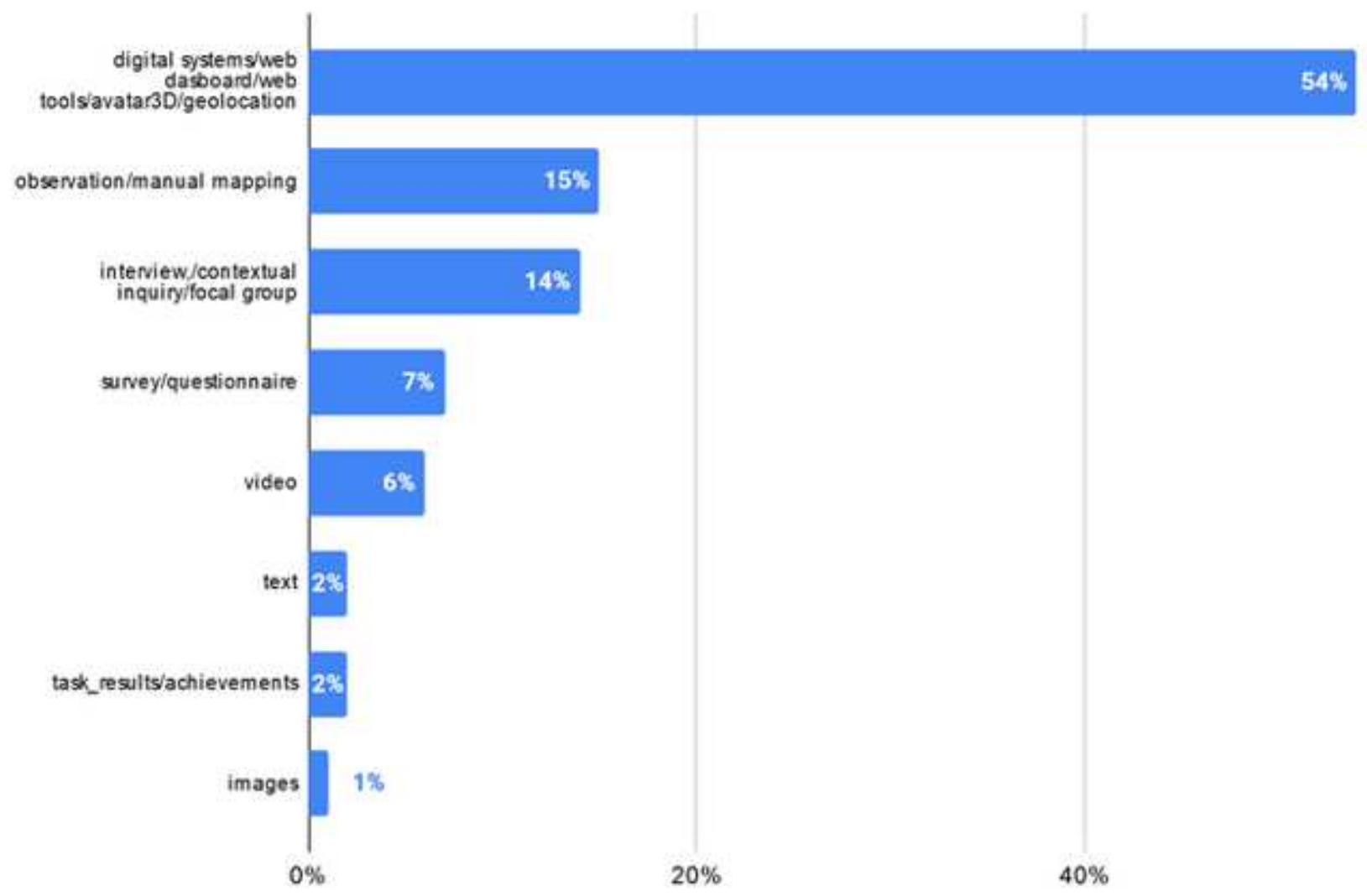

Graphic 2

Figure 2

Instruments used to monitor awareness aspects in learning activities where students move 


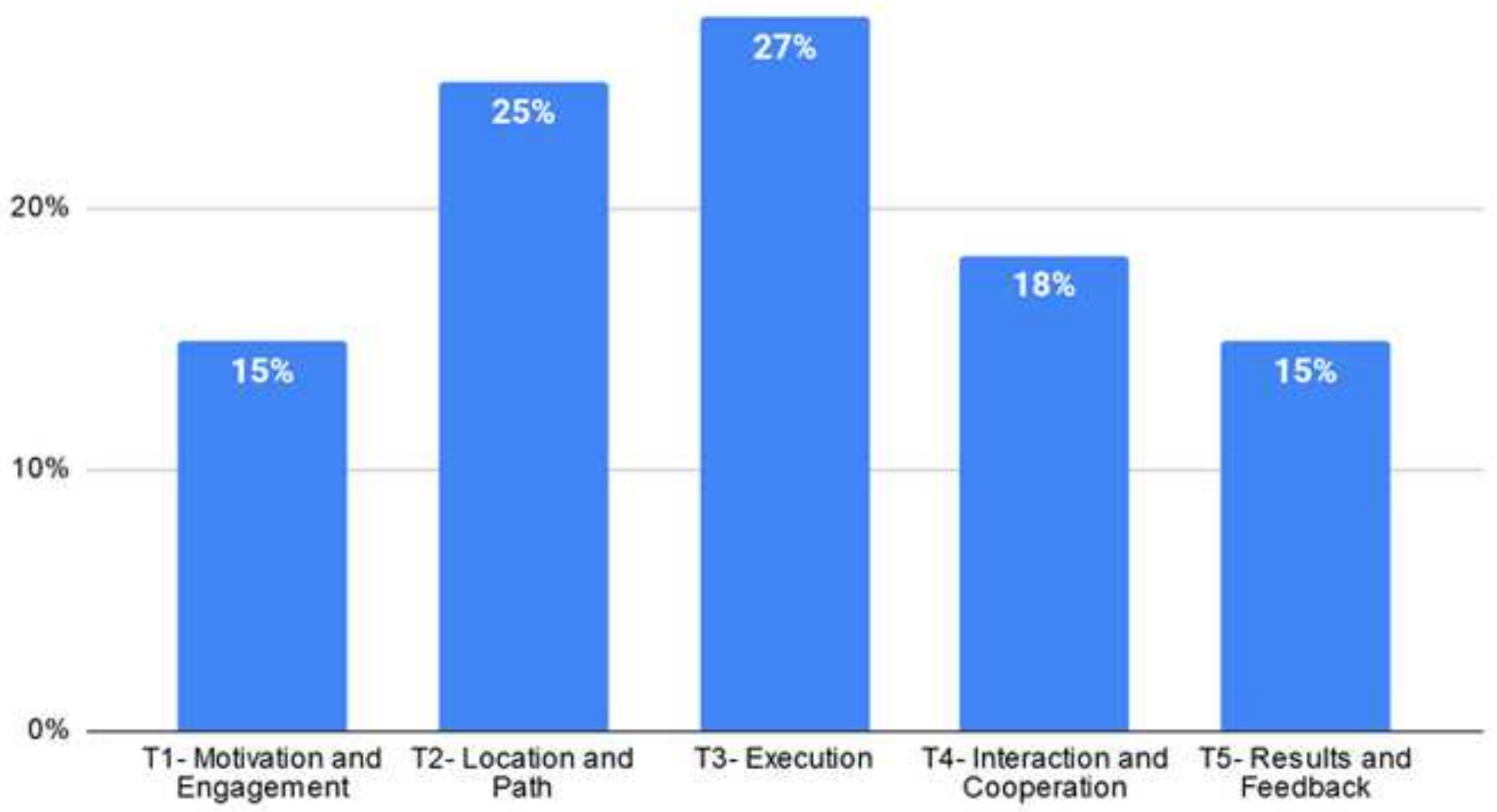

Figure 3

Prevalence of thematic aspects to be observed in mobile activities

\section{Supplementary Files}

This is a list of supplementary files associated with this preprint. Click to download.

- Table1.png

- Table2.png

- Table3.png

- Table4.png

- Table5.png

- Table6.png 